Marquette University

e-Publications@Marquette

College of Nursing Faculty Research and

Publications

Nursing, College of

6-1-1996

Explication of the Construct of Shared Care and the Prevention of Pressure Ulcers in Home Health

Care

Margaret Sebern

Marquette University, margaret.sebern@marquette.edu

Accepted version. Research in Nursing and Health, Vol. 19, No. 3 (June 1996): 183-192. DOI. (C) 1996 John Wiley and Sons.

Margaret Sebern was affiliated with Alverno College at the time of publication. 


\section{Explication of the Construct of Shared Care and the Prevention of Pressure Ulcers in Home Health Care}

By Margaret D. Sebern

The purpose of this investigation was to render a more complete understanding of subjective perceptions of pressure ulcers from the perspective of family dyads, and to study the effect of these subjective experiences on preventive behaviors and pressure ulcer outcomes. $A$ naturalistic inquiry, combined with objective measures, was used. Twenty-one dyads participated in four in-depth interviews to explore how they mentally represented and responded to the risk of pressure ulcers. Through the process of concept development, a lay representation of pressure ulcers was developed. This process produced a new concept, identified as "shared care," that explained how the dyads interaction influenced preventive behavior. Shared care consists of three elements: communication of symptoms, decisions about how to respond to symptoms, and appraisals of reciprocity. Two contrasting patterns of care were identified: shared and directed/discrepant. In the shared care group, 10 patients were at risk for pressure ulcers but only 4 developed ulcers. In this discrepant care group, 3 patients were at risk and 2 developed pressure ulcers. Shared care was a pattern of interaction used successfully by family members to prevent pressure ulcers in patients at risk.

Pressure ulcers continue to pose a serious public health problem in the United States (Agency for Health Care Policy and Research [AHCPR], 1994). The epidemiology of pressure ulcers indicates that they are a serious health threat to the disabled and elderly patient, and a leading cause of prolonged hospitalization and mortality for this group. Pressure ulcers affect approximately $9 \%$ of all hospitalized patients and $23 \%$ of all nursing home patients. The prevalence of pressure ulcers among persons who are cared for in home settings with the supervision of professionals is not fully understood (AHCPR, 1992).

Theories of health behavior emphasize that subjective perceptions influence preventive behavior more than objective risk factors (Becker, 1990; Taylor, 1990; Ward, 1993). Yet, much of what is known about preventing pressure ulcers is based only on investigations of physiological risk factors. Carlson and King (1990) concluded that the role of psychological factors in the prevention of pressure ulcers essentially is unexplored. Subjective perceptions about pressure ulcers are relevant to home health care nurses because the prevention of 
complications, such as pressure ulcers, is dependent on the behavior of the patient and family caregiver.

To provide flexibility, the following definition of family was used, "A family is composed of people (two or more) who are emotionally involved with each other and live in close geographic proximity" (Friedman, 1981, p. 8). The purpose of this investigation was to render a more complete understanding of subjective perceptions of pressure ulcers from the perspective of family dyads, and to study the effect of these subjective experiences on preventive behaviors and pressure ulcer outcomes. A more complete understanding of the dyad's perceptions of pressure ulcer risk and preventive behaviors can be used to develop research and intervention studies to reduce this costly and painful problem.

Self-regulation (Leventhal, 1970, 1990; Leventhal \& Johnson, 1983; Leventhal, Leventhal, \& Schaefer, 1992; Ward, 1993) was selected as a framework to explore the dyad's perceptions of pressure ulcers and coping responses. The self-regulation model has three stages: illness representation, procedures for coping, and appraisals. Representations of illness include symptoms and labels that indicate the threat is present or absent (identity); the individual's perceptions of the cause of the threat (causes); beliefs that the illness is acute, recurring, or chronic (timeline); beliefs that one can influence the illness; and perceptions of the short- and long-term consequences of the illness (consequences). Action plans (coping) are formed in response to the mental representation and evaluations (appraisals) of the action plan and representation.

Nurses and psychologists have employed this model to investigate how to reduce distress in patients undergoing diagnostic and treatment procedures (Barsevick \& Johnson, 1990; Johnson, Lauver, \& Nail, 1989; Leventhal \& Johnson, 1983; Nerenz, Leventhal, \& Love, 1982). Selfregulation has been applied to study behaviors such as medication adherence (Meyer, Leventhal, \& Gutman, 1985), attendance at blood pressure screenings (Zimmerman, Safer, Leventhal, \& Baumann, 1986), and adherence to diabetic regimes (Gonder-Frederick, Cox, Bobbitt, \& Pennebaker, 1986; Hamera, Cassmeyer, \& O'Connell, 1988; O'Connell, Hamera, Schorfheide, \& Guthrie, 1990). The model also was used to explain why people engage in self-treatment of symptoms, and delay seeking health care (Cameron, Leventhal, \& Leventhal, 1993; Prohaska, Funch, \& Blesch, 1990; Safer, Tharps, Jackson, \& Leventhal, 1979). Contextual factors also shape representations. One such factor is social context. For example, communication from family and friends (either accurate or inaccurate) affects representations and coping. Yet, little is known about the substance and impact of these 
sources of communication (Cameron et al., 1993; Leventhal et al., 1992; Leventhal, Leventhal, \& VanNguyen, 1985).

Because self-regulation has proven helpful in understanding and predicting health behavior, it was selected as a guiding framework in the current study. Due to the lack of research using the model in the context of pressure ulcer prevention, a naturalistic inquiry was used for concept development (Knafl \& Deatrick, 1993; Lincoln \& Guba, 1985; Miles \& Huberman, 1984; Morse, 1991; Rodgers \& Knafl, 1993).

Braden and Bergstrom (1987) identify two critical determinants of pressure ulcer risk: (a) the intensity and duration of pressure, and (b) the tissue's tolerance to pressure. Clinical determinants of prolonged pressure are mobility, activity, and sensory perception. Factors affecting tissue tolerance are friction, shear, moisture, nutritional deficiencies, arteriolar pressure, age, and skin temperature (Bergstrom \& Braden, 1990; Braden \& Bergstrom, 1995). The relationships among emerging social psychological themes in the dyad's perceptions and behaviors, physical risk for pressure ulcers, and the incidence of pressure ulcers were examined in order to render a more complete understanding of risk.

\section{Method}

Naturalistic inquiry was used to explore lay representations of pressure ulcers and coping responses of family dyads. This study followed the hybrid model for concept development (Schwartz-Barcott \& Kim, 1986, 1993). There are three phases in the hybrid model: theoretical, empirical, and analytic. The purpose of the theoretical phase is to select and define the concepts for development. The empirical phase is closely associated with the theoretical phase, in that the definition and meaning of the concepts are refined using data generated in qualitative investigations. The purpose of the analytic phase is to justify the initial selection of the concepts. Often new concepts or a reformulation of the initial idea will emerge.

\section{Sample}

Purposive sampling of family dyads was conducted at a midwestern metropolitan Visiting Nurse Association (VNA). To be eligible for the study, members of the dyad had to be 18 years old or older and able to communicate in English; patients had to be limited in ambulating and free of pressure ulcers. The ability of patients and caregivers to communicate was crucial to meeting the aim of the study, which was to conceptualize the dyad's subjective perceptions and coping responses to pressure ulcer risk. 
The visiting nurses invited family members to participate. All subjects received written and verbal information about the study and gave written consent. Thirty families were invited to participate; 9 of these families refused or later withdrew from the study. Reasons for refusal included patient unwillingness to undergo skin inspection, lack of time to participate, and disinterest in talking about pressure ulcers. The final sample consisted of 21 families, or 42 subjects.

The mean age of the patients was 73 years (range 22-97 years, $S D=17$ ); for the family caregivers, it was 65 years (range 40 to $87, S D=13$ ). Thirteen of the dyads were married, and 2 were male/female partners living together. Four dyads were daughters caring for a parent, 1 dyad was a mother caring for her son, and 1 was a woman caring for her friend. The gender, race, education, income, and diagnoses of the sample are summarized in Table 1 . All patients had three or more chronic conditions. The most frequent patient diagnoses were urinary incontinence or retention $(n=11)$, diabetes $(n=7)$, and urinary tract infection $(n=6)$.

Quadriplegia was a neurological complication in 5 of the patients. The most frequent caregiver diagnoses were arthritis $(n=9)$ and hypertension $(n=8)$.

\section{Measures}

\section{Qualitative interview}

A two-part open-ended interview guide was developed, based on a review of the selfregulation literature. In the first part of the interview, questions were asked about pressure ulcer identity, symptoms, consequences, causes, and timeline. In the second section, self-care responses were elicited by asking dyads to describe actions taken to maintain skin integrity, prevent pressure ulcers, or heal pressure ulcers. Subjects were asked how effective their care was, and if there were things they knew would help that they could not do. Content validity for the interview guide was assessed by four experts in the areas of self-regulation theory, concept development, and measurement research.

\section{Braden scale}

Physiological risk factors and the incidence of pressure ulcers were measured using the Braden Scale and a skin assessment tool. The Braden scale groups physiological risk factors into six subscales that reflect sensory perception, skin moisture, activity, mobility, friction and shear, and nutritional status. The subscales are rated 1 (least favorable) to 3 or 4 (most favorable). The minimum score is 6 , and the maximum is 23 ; a low score indicates a high risk for pressure ulcers. Of the major assessment instruments for pressure ulcer risk, the Braden scale demonstrates the most promise (Bergstrom \& Braden, 1990, 1992; Bergstrom, Braden, 
Laguzza, \& Holman, 1987; Bergstrom, Demuth, \& Braden, 1987; Braden, 1990; Braden \& Bergstrom, 1989, 1995). The predictive validity of the Braden scale has been tested with a sample of home care patients $(n=103)$. A score of 17 and lower was found to be predictive of pressure ulcers (B.J. Braden, personal communication, April 10, 1992).

\section{Skin assessment tool}

The incidence of pressure ulcers was measured with the Bergstrom skin assessment tool (Bergstrom, 1989). The Bergstrom tool contains pressure ulcer definitions and is consistent with the recommendations of the AHCPR (1992). A reliability study (Sebern, 1992) of this instrument was conducted at a Visiting Nurse Association (VNA) to determine if the visiting nurses (RN) could agree on the classification of pressure ulcers. There was good interrater reliability and the coefficient of concordance (W) for the RNs was .81 $(n=45)$.

\section{Procedures}

A series of four interviews were conducted in the family's home to explore how dyads subjectively perceived and prevented pressure ulcers. In the first interview, the patient and family caregiver were interviewed separately to elicit their beliefs and their actions to care for the patient's skin. Subsequent interviews, every 2 to 4 weeks, were based on questions, themes, and working hypotheses identified by the investigator after reviewing the transcript from the previous interview. Credibility of the qualitative data (Lincoln \& Guba, 1985) was established by tape recording all interviews, transcribing tapes verbatim, seeking feedback from the participants regarding tentative interpretations of data, and making repeated contacts. A total of 84 contacts with family members were made. At the end of each interview, the investigator assessed the patient's risk with the Braden scale. Following each of the investigator's home visits, the visiting nurse assessed the patient for pressure ulcers using the skin assessment tool.

Confirmability of findings was maintained with an audit trail; all results from the analysis of data can be traced back to the narrative data. The audit trail was established by coding the narrative data and writing memos to explain the codes using the computer program Martin (Diekelmann, Schuster, \& Lam, 1990). The codes were deductively derived from concepts of selfregulation and defined in a code book. The code book included definitions for identity, symptoms, location, labels, timeline, causes, consequences, self-care responses, and appraisals of pressure ulcers and the effectiveness of care. In addition to coding the narrative data, case summaries were completed for each family. Summaries for each dyad were organized in a framework consistent with the study's conceptual framework of representations, self-care, and appraisals of skin integrity. 
The relationships between Braden scores, incidence of pressure ulcers, and social psychological concepts emerging from the narrative data were explored through matrix display techniques described by Miles and Huberman (1984). For example, family care themes (shared and discrepant) were used to sort the patients' Braden scores and occurrences of pressure ulcers. The computer program Paradox (Borland International, 1990) was used to construct and display matrices.

\section{Results}

The technique of constant comparison was used to identify themes in pressure ulcer representations and coping, in each dyad and across dyads. A consistent finding across dyads was that there were separate roles for shaping pressure ulcer representations. For example, the caregiver provided information about the appearance of the skin, and the patient provided sensory information. The following narrative demonstrates the different roles of one patient (MK) and family caregiver (CK) in communicating symptoms. MK was respirator dependent, at risk for pressure ulcers (Braden score $=14$ ), and successfully maintained his skin integrity.

MK: I think, I never thought of this before I got bedridden. Me knowing and feeling everywhere in my body, I know when I am getting sore, and I alert Mom and Dad to that.

When the patient communicated sensory discomfort, the caregiver's role was to assess the appearance of the skin, and to do something about the symptoms. In the following narrative the caregiver describes her role in assessing the skin.

CK The minute it gets red it is a bedsore to me. What you will see is one corner of the old scar start to bleed and we will get at it right away. And it is gone right away.

\section{Representations}

The lay representation of pressure ulcers differs from the professional definition in several categories. First, none of the dyads used the label pressure ulcer; the label they used was bedsore. The lay beliefs about symptoms of bedsores were that they are open sores that drain and get bigger. The patients who experienced a bedsore reported early symptoms of the skin hurting, itching, burning, "felt funny, but was nothing bad." Only one caregiver believed that 
nonblanchable erythema was a bedsore. Subjects frequently stated that bedsores are located on the back or buttocks.

Lay beliefs about causes were categorized as internal and external causes. The most prevalent belief was that bedsores are caused by the internal factor of being unable to move (14 patients, 20 caregivers). Other stated causes included the inability to walk (3 patients, 4 caregivers), and moisture/incontinence (3 patients, 5 caregivers). No individual mentioned that sensory impairment was a potential cause for bedsores. Less frequently, bedsores were attributed to external factors, including poor care (3 patients, 5 caregivers), and friction, shear, and pressure (5 patients, 7 caregivers). The timeline for bedsores was that they take weeks to develop, and may never heal. One dyad believed bedsores are recurring problems.

Consequences of bedsores were that they interfere with activities of daily living (6 patients, 1 caregiver), the individual would have to seek information about what to do (3 patients, 13 caregivers), and it would involve more work to take care of the bedsore (3 patients, 15 caregivers). The emotional consequences of bedsores for caregivers was that they would feel bad for the patient, and blame themselves for it. The patient would also feel "bad" if a bedsore developed. In summary, the study participants represented bedsores as large draining ulcers, caused by not being able to move. They believed that bedsores are located on the back and buttocks, and that the caregiver would have to learn how to treat them.

\section{Care Content}

Consistent with the techniques of concept development, a new construct emerged from the analysis, and was named shared care. Shared care explains how dyads interact to maintain skin integrity. A contrasting pattern of care emerged, and was labeled directed/discrepant care.

\section{Shared care}

Three elements of shared care are: clear communication of symptoms, patient decisional control, and reciprocity among family members. Thirteen of the 21 families were classified as shared care. Ten of the patients in shared care were at risk (Braden score 5 17), but only 4 developed pressure ulcers.

The first characteristic of shared care is clear communication and prompt relief of symptoms. The patient communicated concrete symptoms of discomfort, and the caregiver assessed and communicated the appearance of the skin. Part of this communication involves agreement about the meaning of the symptoms, and what ought to be done to relieve the symptoms. The following caregiver narrative describes this agreement about what should be done: 
CK: If he is uncomfortable you know it, he will tell one of us. We will go in and move one of his arms, he will say I feel like my arm needs stretching. So I will go in and stretch his arm. Other than the hips he is comfortable.

Family members reported they automatically responded to symptoms such as incontinence, skin redness, and discomfort. Families were motivated to act to relieve symptoms, but did not necessarily believe they were preventing pressure ulcers. The following narrative from the shared care group demonstrates the role of symptoms, but not the threat of pressure ulcers, in directing the caregiver's $(\mathrm{CH})$ preventive behaviors. $\mathrm{DH}$ was 94 years old with diagnoses of arthritis and osteoporosis, at risk (Braden score $=17$ ), and did not develop a pressure ulcer.

$\mathrm{CH}$ : I don't do anything for bedsores. But just the normal washing and, of course, I keep eyes on her skin. If she would get moist, if she would urinate her pants will be wet, her shields will be wet, her legs will get wet, and you make sure it is dry. And she has dry clean clothes to put on.

INT: You do that to protect her skin?

$\mathrm{CH}$ : Well, you do that automatically, that is just normal, you are not going to let her sit there like that.

Thus, clear communication and symptom relief directed preventive behaviors. The second characteristic of shared care is patient decisional control. For the purpose of this study, decisional control was defined as decision making aimed at exerting influence over events and conditions in the patient's environment. In shared care the patient's evaluation of the situation was the basis for action. For example, LB was respirator dependent, at risk (Braden score = 15), and developed ulcers. His control over decision making is evident in the following narrative.

INT: You make all the decisions about your skin care?

LB: With M. (MB).

MB: I just answer his questions because I have the sight to see which he doesn't. But I think we have been on a long road with many problems, and the best way to handle them are for me to be his eyes, and let him make up his mind. There is nothing wrong with the way his mind works. And he is very logical so together we operate well that way. I can tell him what it looks like. I can tell him what I think and then he can make up his own mind. He is responsible for his own body. And that works well ... He is very much in charge so he lets us, anybody that is taking care of him, know what he thinks ought to be done. And he talks to the 
doctor. So, even though he can't see it, he has enough feeling so he knows what is going on.

The third characteristic of shared care is reciprocity among the family members. The reciprocal behaviors between study participants were within the limits of each person's physical and psychological capabilities. Reciprocity was evident in family members' statements of appreciation and gratitude for each other's contribution to shared care. The caregivers expressed reciprocity by talking about how patients participated in care within the limits of their disabilities. Patients exhibited reciprocity in statements that they did not want to be a burden for the caregiver, and that they wanted to do as much as they could for themselves. The following patient narrative exhibits the patient's gratitude and contribution to the shared care relationship. JR had a cerebral vascular accident resulting in right hemiplegia, was at risk (Braden score = 16), and developed a Stage I pressure ulcer that healed.

JR: She (SC) is so helpful 1 don't know what I would do without her. With her help I am still sticking around. I want to keep improving too. As much as I can, I stand by the bed three or four times a day and straighten the leg out.

To summarize, in 13 shared care dyads preventive behaviors were influenced by clear communication and relief of symptoms, patient decisional control, and reciprocity between the patient and caregiver. Shared care was a pattern of interaction used by families to try to prevent pressure ulcers in patients at risk. Four out of the 10 shared care dyads at risk developed ulcers. In these four patients all but one patient's ulcer healed. This one patient had recurring pressure ulcers due to social activities requiring him to be up in his wheel chair. This patient did not want to give up his social activities in order to prevent pressure ulcers.

One shared care patient not at risk (Braden score $=19$ ) developed two pressure ulcers on his heels when hospitalized for open heart surgery. One of the pressure ulcers resulted in the amputation of his leg. This patient had several chronic conditions that contributed to poor health (insulin-dependent diabetes, peripheral neuropathy, retinopathy resulting in blindness, renal failure, and congestive heart failure). Thus chronic illness resulting in multisystem failure and surgery contributed to this patient's risk. Medical diagnoses and surgery are not measured by the Braden scale; this finding points to the need for more than one measurement of pressure ulcer risk.

\section{Directed/discrepant care}

Eight dyads were classified as directed/discrepant care. Unlike the clear communication in shared care, in directed/ discrepant care there is delay or conflict in communicating and 
relieving symptoms, conflict in decision making, and less reciprocity in care. Only three patients in this group were at risk and two developed pressure ulcers. One patient not at risk (Braden score $=21$ ) developed an ulcer. This 73-year-old woman had multiple chronic conditions (incontinence, femoral popliteal bypass surgery, hypertension, skin cancer, cerebral vascular accident, osteoporosis, and arterial insufficiency). When she developed a Stage I ulcer on her ankle, she denied it was a pressure ulcer and refused to follow through on suggestions to relieve pressure. She states in the following narrative that the ulcer is "dry skin."

LM: Well Nancy (visiting nurse) said she thought it would break open, and I think it was just dry skin because the other day even the bottom of my foot, in the middle of my foot 1 could feel that it was, it hurt kind of, and it itched, too. That was dryness.

Directed/discrepant care patients consciously or unconsciously underreported their symptoms. The caregivers were uncertain whether patients have bedsores because patients do not provide information about the skin breakdown. Another patient, 73 years old and in the terminal stage of lung cancer, was at risk (Braden score $=12$ ) and had Stage II ulcers at the time of this interview. The inattentiveness of the patient to his symptoms and the attentiveness of the caregiver was evident in the following narrative.

INT: Are you aware you have a bedsore?

MY: No.

INT: Has your husband had any pressure ulcers?

HY: Like I said I think they are starting, I am not sure. There is one on his right hip, right above his buttock in the center, I think there may be one on his left shoulder.

Thus, the patient's lack of communication about his symptoms leads to the caregiver's uncertainty in her representation and care responses for skin breakdown. In addition to delay in communicating and relieving symptoms, the following narrative demonstrates conflict over the meaning of symptoms. VT was 85 years old, with the diagnosis of inability to void, arthritis, hypertension, and asthma. She was at risk (Braden score $=17$ ) but did not develop ulcers. This patient reported during the interview that she frequently falls while walking.

INT Are you still getting sore from sitting in the chair?

VT: I guess I am just getting used to it, it isn't comfortable.

JT (CG): She hasn't complained lately. 
VT: I am getting used to it.

INT: What is uncomfortable in the morning?

VT: My back starts to hurt, I sometimes have to wait a couple of hours before I call him. He needs his sleep and I don't.

INT: What is the cause of your back hurting?

VT: I fell last time. It hurts more than it did. The other way it hurts was I was on it all night.

Different interpretations of the symptoms (discomfort verses complaining) led the patient to delay reporting her symptoms, and the caregiver to delay in repositioning her. Clearly, remaining in the same position after the onset of discomfort puts directed/discrepant patients at risk for pressure ulcers. Another discrepancy for the dyad was in their representations of her falls. The patient reported that she believed she fell because her legs get weak and give out. The caregiver believed the patient fell because she did not walk enough and was inactive.

Unlike patient decisional control in shared care, in directed/discrepant dyads there was conflict in decision making. Often the caregiver's representation was more important in making treatment decisions. $\mathrm{CH}$ explained how she agreed to the placement of a gastrostomy tube in AH even though the patient did not want it. AH was 72 years old and had a history of a cerebral vascular accident and diabetes, was not at risk (Braden score $=19$ ), and did not develop ulcers.

$\mathrm{CH}$ : I said AH you are going to have to have another tube in. He said 1 don't want another tube. I said you got to live. That is the only way you are going to live. He said let me die. I said did you ever die from starvation. He said what do you mean? I said it is a horrible death, don't be stupid. Then they put the tube in. He was no good after that.

In addition to conflict over patient care decisions, there was less reciprocity between the family members. For example family members reported dissatisfaction with the present care relationship, and some patients did not adhere to medication and exercise regimes.

Dissatisfaction with care is evident in the following narrative.

RM: My life is totally different, totally. I do everything, shopping, managing, cooking, helping her.

LM: He has to help me from morning to night.

INT: Does this limit your activities?

RM: Absolutely.

LM: It is not a good arrangement. It is very difficult for both of us. 
To summarize, the term shared care was used to describe how family members interact to shape pressure ulcer representations and care responses. This interaction involves communication of symptoms, decisions about how to respond to symptoms, and appraisals of reciprocity. Patterns of care (shared and directed/discrepant) vary in terms of clarity in communication, delays in relief of symptoms, decisional control, and reciprocity. Shared care was related to preventive behaviors such as skin assessment and hygiene, repositioning, ambulating, medication adherence, and exercise. The findings for directed/ discrepant care were not as clearcut compared to shared care, but directed/discrepant care was conceptualized as a pattern of interaction placing the patient at risk for pressure ulcers.

\section{Discussion}

The use of the self-regulation model contributed to understanding the lay representation of pressure ulcers and preventive actions. The emergence of the construct of shared care provides a more complete understanding of how the dyads' interactions contributed to preventive care and pressure ulcer outcomes.

The conceptualization of shared care has several clinical and research implications. First, clarity in symptom communication between dyad members is important. Leventhal et al. (1985) suggest that each family member will have his or her own representation of a health threat. When there is clear communication about the threat, however, there can be overlap in the family members' representations. In Feetham's (1984) review of the family literature, communication was identified as an important component of family assessment. In this inquiry, the patient was repositioned when the dyad agreed that the patient was uncomfortable. On the other hand, when a caregiver believed the patient's discomfort was "complaining," there was a delay in relieving symptoms. A clinical implication of these findings is that the family's pattern of communicating symptoms should be assessed when planning preventive interventions. When conflict in communication is assessed, interventions should focus on facilitating clear communication.

Preventive behavior did operate independently of the threat of pressure ulcers. For example, family members stated they automatically responded to symptoms of sitting discomfort, redness, and incontinence. They did not necessarily believe they were preventing pressure ulcers. Investigators assert that concrete symptoms function to activate existing coping responses (Cameron et al., 1993; Leventhal \& Johnson, 1983). Because perceptual information is more salient than abstract information about risk, interventions should include information about concrete symptoms of tissue ischemia and how to manage these symptoms. 
The dyad's specific roles in the communication of symptoms also has clinical implications. Because of the patient's role in communicating sensations of actual and potential skin breakdown, he or she may more easily assimilate information about sensory discomfort caused by tissue ischemia. Similarly, having taken on the role of reporting the appearance of the skin, the caregiver may more readily accept information about skin assessment. Of course, the specifics of these roles may vary in different populations. Had these patients been capable of skin assessment with a mirror, they might have taken on this role. As it was, in this sample use of a mirror was not practical due to visual impairments, lack of dexterity to hold a mirror, and being "just too hard to do."

In addition to the communication and relief of symptoms, decisional control and reciprocity emerged as key components of shared care. In the health behavior literature, decisional control is described as the act of participating in decision making, resulting in a sense of increased influence and control (Israel \& Schurman, 1990; Lewis \& Daltroy, 1990). Lewis and Daltroy contend that a shift in attributions of control is particularly important in chronic illness. They assert that interventions should shift the person's attributions from an area over which they have little or no control (e.g., physical function), to an area over which they can maintain control (e.g., decisions about care). In this investigation, severely disabled patients exerted control over their environment by maintaining decisional control. Decisional control may lessen the stress caused by chronic illness, and contribute to positive health outcomes like the prevention of pressure ulcers. It follows from these findings that patients should be involved in decisions about care and that interventions that facilitate patient decisional control should be developed and tested.

Another dimension of shared care is reciprocity. In the social support and family literature, investigators emphasize the significance of reciprocity (Cohen \& Syme, 1985; Given \& Given, 1991; Kane, 1988; Roy \& Andrews, 1991; Stewart, 1993). Roy and Andrews (1991) conceptualize reciprocity as integral to the interdependence mode of human adaptation. Interdependence is defined as giving and receiving love, value, and respect. The basic need underlying the mode is the human need to feel secure in nurturing relationships. According to Roy and Andrews, effective functioning in the interdependence mode contributes to adaptation to stressful events. Given and Given (1991) also identified mutuality and recognition as important to buffering stress in family caregivers who care for the chronically ill.

Reciprocity contributed to different care patterns. In shared care each member of the dyad contributed to preventive care within the limits of physical capabilities. By contrast, directed/ discrepant dyads at times did not participate in care. For example, directed/discrepant 
care patients underreported symptoms, and did not adhere to treatment recommendations. These behaviors could place the patient at risk for pressure ulcers due to delay in reporting and responding to symptoms, lack of adherence to medication and exercise regimes, and stress caused by negative interactions in the dyad. Stewart (1993) suggests that negative interactions, such as disagreement with personal interpretations, is a detrimental feature of support.

The observation that patients who were not at risk (based on their Braden scores) developed pressure ulcers suggests that one measure should not be the sole factor in determining pressure ulcer risk. For example, the Braden scale does not measure multisystem organ failure. Therefore, multiple physiological and human behavior frameworks are critical to risk assessment.

Only patients and caregivers who could communicate were interviewed. Interactions among family members when the patient is cognitively impaired or aphasic were not explored. Dyads including cognitively impaired patients could be conceptualized as directed/discrepant care because the patient cannot clearly communicate symptoms or make decisions and, thus, these patients may be at risk for pressure ulcers. This possibility should be explored.

Further research focused on instrument development to measure patterns of care, and the association between patterns of care, physiological risk, preventive health behaviors, and the incidence of pressure ulcers is needed. The patterns of care identified in this study have implications for developing clinical interventions aimed at facilitating clear communication, patient decisional control, and reciprocity among family dyads.

\section{References}

Agency for Health Care Policy and Research (1992). Clinical practice guideline number 3.

Pressure ulcers in adults: Prediction and prevention. Rockville, MD: Author. (AHCPR Publication No. 92-0047).

Agency for Health Care Policy and Research (1994). Clinical practice guideline number 15.

Pressure ulcer treatment. Rockville, MD: Author. (AHCPR Publication No. 92-0047).

Barsevick, A.M., \& Johnson, J.E. (1990). Preference for information and involvement, information seeking, and emotional responses of women undergoing colposcopy. Research in Nursing \& Health, 13, 1-7.

Becker, M.H. (1990). Theoretical models of adherence and strategies for improving adherence. In S.A. Shumaker, E.B. Schron, \& J.K. Ockene (Eds.), The handbook of health behavior change (pp. 5-43). New York: Springer. 
Bergstrom, N. (1989). Protocol for testing the Braden Pressure Sore Predictor Scale. Unpublished protocol. University of Nebraska.

Bergstrom, N., \& Braden, B.J. (1990). Nutritional status during the development and resolution of pressure ulcers. In S.G. Funk, E.M. Tornquist, M.T. Champagne, L.A. Copp, \& R.A. Wiese (Eds.), Key aspects of recovery (pp. 183-187). New York Springer.

Bergstrom, N., \& Braden, B.J. (1992). A prospective study of pressure ulcer risk among institutionalized elderly. Journal of the American Geriatrics Society, 40, 747-758.

Bergstrom, N., Braden, B.J., Laguzza, A., \& Holman, V. (1987). The Braden scale for predicting pressure ulcer risk. Nursing Research, 36, 205-210.

Bergstrom, N., Demuth, P., \& Braden, B.J. (1987). A clinical trial of the Braden scale for predicting pressure ulcer risk. Nursing Clinics of North America, 22, 417-428.

Borland International. (1990). Paradox relational database (Version 3.5) [Computer program manual]. Scotts Valley, CA: Author.

Braden, B.J. (1990). The relationship between emotional stress and pressure ulcer formation among elderly recently relocated to a nursing home. In S.G. Funk, E.M. Tornquist, M.T. Champagne, L.A. Copp, \& R.A. Wiese (Eds.), Key aspects of recovery (pp. 188- 196). New York: Springer.

Braden, B.J., \& Bergstrom, N. (1987). A conceptual schema for the study of the etiology of pressure ulcers. Rehabilitation Nursing, 12, 8-12.

Braden, B.J., \& Bergstrom, N. (1989). Clinical utility of the Braden scale for predicting pressure ulcer risk. Decubitus, 2 (3), 44-51.

Braden, B.J., \& Bergstrom, N. (1995). Predictive validity of the Braden Scale for pressure sore risk in a nursing home population. Research in Nursing \& Health, 17, 459-470.

Cameron, L., Leventhal, E. A., \& Leventhal, H. (1993). Symptom representation and affect as determinants of care seeking in a community dwelling, adult sample population. Health Psychology, 12, 171-179.

Carlson, C.E., \& King, R.B. (1990). Prevention of pressure sores. Annual Review of Nursing Research, 8, 35-56.

Cohen, S., \& Syme, S.L. (1985). Social support and health. New York: Academic Press.

Diekelmann, N., Schuster, R., \& Lam, S. (1990). Martin [Computer program]. Madison, WI: University of Wisconsin-Madison.

Feetham, S.L. (1984). Family research: Issues and directions for nursing. Annual Review of Nursing Research, 2, 3-26. 
Friedman, M. (1981). Family nursing: Toward theory and assessment (2nd ed.). New York: Appleton- Century-Crofts.

Given, B.A., \& Given, C.W. (1991). Family caregiving and the elderly. Annual Review of Nursing Research, 10, 77-102.

Gonder-Frederick, L.A., Cox, D.J., Bobbit, S.A., \& Pennebaker, J.W. (1986). Blood glucose symptom beliefs of diabetic patients: Accuracy and implications. Health Psychology, 5, 327-341.

Hamera, E,, Cassmeyer, V., \& O'Connell, K.A. (1988). Self-regulation in individuals with Type II diabetes. Nursing Research, 37, 363-367.

Israel, B. A., \& Schurman, S. J. ( 1990). Social support, control, and the stress process. In K. Glanz, F.M. Lewis, \& B.K. Rimer (Eds.), Health behavior and health education theory, research, and practice (pp. 92-114). San Francisco: Jossey-Bass.

Johnson, J., Lauver, D., \& Nail, L. (1989). Process of coping with radiation therapy. Journal of Consulting and Clinical Psychology, 57, 358-364.

Kane, C.F. (1988). Family social support: Toward a conceptual model. Advances in Nursing Science, 10 (2), 18-25.

Knafl, K.A., \& Deatrick, J.A. (1993). Knowledge synthesis and concept development in nursing. In B.L. Rodgers \& K.A. Knafl (Eds.), Concept development in nursing: Foundations, techniques, and applications (pp. 35-50). Philadelphia: Saunders.

Leventhal, H. (1970). Findings and theory in the study of fear communications. Advances in Experimental Social Psychology, 5, 119-186.

Leventhal, H. (1990). Emotional and behavioral processes. In M. Johnston \& L. Wallace (Eds.), Stress and medical procedures (pp. 25-57), New York: Oxford University Press.

Leventhal, H., \& Johnson, J.E. (1983). Laboratory and field experimentation: Development of a theory of self-regulation. In P.J. Wooldridge, M.H. Schmitt, J.K. Skipper, Jr., \& R.C. Leonard (Eds.), Behavioral science and nursing theory (pp. 189-262). St. Louis: Mosby.

Leventhal, H., Leventhal, E. A., \& Schaefer, P.M. (1992). Vigilant coping and health behavior. In M.G. Ory, R.P. Abeles, \& P.D. Lipman (Eds.), Aging, health, and behavior (pp. 109-140). Newbury Park: Sage.

Leventhal, H., Leventhal, E.A., \& Van Nguyen, T. (1985). Reactions of families to illness:

Theoretical models and perspectives. In D. Turk \& R. Kerns (Eds.) Health, illness, and families: A life-span perspective (pp. 108-145). New York: Wiley.

Lewis, F.M., \& Daltroy, L.H. (1990). How causal explanations influence health behavior: Attribution Theory. In K. Glanz, F.M. Lewis, \& B.K. Rimer (Eds.), Health behavior and 
health education theory, research, and practice (pp. 92-1 14). San Francisco: JosseyBass.

Lincoln, Y.S., \& Cuba, E.G. (1985). Naturalistic inquiry. Newbury Park: Sage.

Meyer, D., Leventhal, H., \& Gutmann, M. (1985). Common sense models of illness: The example of hypertension. Health Psychology, 4, 1 15- 135.

Miles, M.B., \& Huberman, A.M. (1984). Qualitative data analysis: A sourcebook of new methods. Newbury Park: Sage.

Morse, J.M. (1991). Approaches to qualitative-quantitative methodological triangulation. Nursing Research, 40, 120-123.

Nerenz, D.R., Leventhal, H., \& Love, R.R. (1982). Factors contributing to emotional distress during cancer chemotherapy. Cancer, 50, 1020- 1027.

O'Connell, K.A., Hamera, E.K., Schorfheide, A., \& Guthrie, D. (1990). Symptom beliefs and actual blood glucose in Type 11 diabetes. Research in Nursing \&Health, 13, 145-151.

Prohaska, T.R., Funch, D., \& Blesch, K.S. (1990). Age patterns in symptom perception and illness behavior among colorectal cancer patients. Behavior, Health, and Aging, 1, 27-39.

Rodgers, B.L., \& Knafl, K.A. (1993). Concept development in nursing: Foundations, techniques, and applications. Philadelphia: Saunders.

Roy, C., \& Andrews, H.A. (1991). The Roy Adaptation model: The definitive statement. Nonvalk: Appleton \& Lange.

Safer, M.A., Tharps, Q.J., Jackson, T.C., \& Leventhal, H. (1979). Determinants of three stages of delay in seeking care at a medical clinic. Medical Care, 17, 11-29.

Schwartz-Barcott, D., \& Kim, H.S. (1986). A hybrid model for concept development. In P.L. Chinn (Ed.), Nursing research methodology: Issues and implementation (pp. 91-101). Rockville, MD: Aspen.

Schwartz-Barcott, D., \& Kim, H.S. (1993). An expansion and elaboration of the hybrid model of concept development. In B.L. Rodgers \& K.A. Knafl (Us.), Concept development in nursing: Foundations, techniques, and applications (pp. 107-133). Philadelphia: Saunders.

Sebem, M.D. (1992). Symptom beliefs and shared care in home health patients and family caregivers. Dissertation Astracts International, 53 (08), 4,036B. (University Microfilms No. 9238024)

Stewart, M.J. (1993). Integrating social support in nursing. Newbury Park: Sage.

Taylor, S.E. (1990). Health psychology: The science and the field. American Psychologist, 45, 40-50. 
Ward, S.E. (1993). The common sense model: An organizing framework for knowledge development in nursing. Scholarly Inquiry for Nursing Practice, 7, 79-90.

Zimmerman, R.S., Safer, M.A., Leventhal, H., \& Baumann, L.J. (1986). The effects of health information in a worksite hypertension screening program. Health Education Quarterly, 13, 261-280. 


\section{Appendix}

\section{Table 1: Demographic Information}

\begin{tabular}{lll}
\hline & \multicolumn{1}{c}{ Patient $(n=21)$} & Caregiver $(n=21)$ \\
\hline Mean age & 73 years & 65 years \\
Gender & 10 female & 14 female \\
& 11 male & 7 male \\
Race & 18 White & 18 White \\
Median education & 3 African-American & 3 African-American \\
Median income & \$15,000-\$19,000 & 12 years \\
Diagnoses & Urinary incontinence (11) & A15,000-\$19,000 \\
& Diabetes (7) & Hypertension (8) \\
& Urinary tract infection (6) & None (4) \\
& Cerebral vascular accident (5) & \\
& Chronic obstructive lung disease (5) & \\
& Congested heart failure (4) & \\
& Pneumonia (4) & \\
& Chronic skin disease/stasis ulcer (4) & \\
& Osteoporosis (2) & \\
& Degenerative neurological disease (3) \\
\end{tabular}

